\title{
Morphological and physiological lesions induced by micropropagation
}

\author{
A. Harbour ${ }^{1,2}$, C.J. Atkinson ${ }^{1}$, K. Oates ${ }^{1}$ and W.J. Davies ${ }^{1}$ \\ 1 Institute of Environmental and Biological Sciences, University of Lancaster, Lancaster, LA1 4YQ, \\ and \\ 2 Neoplants Ltd., Freckleton, Lancashire, PR4 1HU, U.K.
}

\section{Introduction}

Weaning of plantlets produced in micropropagation often requires an extended period of growth in a fogging facility. This treatment reduces the risk of damage due to desiccation when plantlets are removed from culture. Desiccation injury is a particular problem because of limited development of cuticle, abnormal stomatal behaviour and abnormal xylem development in plants raised by these techniques. While effects of culture conditions are generally well understood, much less attention has been directed at any morphological and physiological lesions induced by conditions employed during weaning.

Photinia fraseri Red Robin is an evergreen woody shrub prized for its bright red young foliage. This plant can be multiplied successfully in culture and will root effectively in compost shortly after transfer from a rooting medium. Problems were observed initially with plants that had been in a fogging house for $20 \mathrm{~d}$. Older leaves of well-rooted plants became flaccid, followed rapidly by browning and death of the whole plant. No pathological symptoms were detected. Preliminary observations suggested that a reduced exposure to fogging treatment resulted in reduced plant loss and therefore experiments were conducted where the effects of different weaning conditions on structure and physiology of leaves were investigated.

\section{Materials and Methods}

On 3 different occasions, plants were transferred from culture to a peat-based compost contained in modular trays. These trays were placed in the fogging house for $7 \mathrm{~d}$ or $21 \mathrm{~d} \mathrm{be}$ fore they were moved to the greenhouse. Plants were: a) 'fogged' in autumn 1987; b) 'fogged' in early summer 1988; c) 'fogged' in late summer 1988. Greenhouse conditions for plants from groups a and $c$ were generally cool and humid, while plants in group b were exposed to hot and dry conditions.

Samples of fresh leaf tissue were taken and frozen in slushy nitrogen prior to examination under the scanning electron microscope (SEM). Material was prepared on the freezing stage of the Joel JSM 840A microscope, coated with gold and examined at $8 \mathrm{kV}$.

Gas exchange of single leaves was monitored in a system similar to that described by Atkinson, (1986). All measurements were made on young fully expanded leaves that had been initiated and had expanded at least partly in the 
fog-house. Experimental conditions were: leaf temperatures $23^{\circ} \mathrm{C}, \mathrm{O}_{2} 21 \%$, PAR $1000 \mu \mathrm{mol}$ $\mathrm{m}^{-2} \mathrm{~s}^{-1}$, and $\Delta w 10 \mathrm{mmol} \mathrm{mol}^{-1}, \mathrm{CO}_{2}$ assimilation rate $(A)$ was measured at various ambient $\mathrm{p}\left(\mathrm{CO}_{2}\right)$ and $A / C_{i}$ (intercellular $\mathrm{CO}_{2}$ concentration) analysis was performed (Farquhar and Sharkey, 1982). Plants examined using the above techniques were of a comparable age (i.e., $7 \mathrm{~d}$ fog $+21 \mathrm{~d}$ in geenhouse or $21 \mathrm{~d}$ fog and $7 d$ in greenhouse).

\section{Results}

There was a high mortality rate of plants from group a that had received $21 \mathrm{~d}$ fog, while many plants from group $c$ that had received $7 \mathrm{~d}$ fog also died. Plants from group b showed very low mortality. Exami- nation of the abaxial surface of leaves of plants from group a showed that $7 \mathrm{~d}$ fogging resulted in apparently normal leaf development, while plants that had received $21 \mathrm{~d}$ fogging showed abnormal stomatal development (Fig. 1). 'Normal' leaves had a stomatal density of approximately $50 \mathrm{~mm}^{-2}$, while extended fogging resulted in the normal development of less than half this number of stomata. Pores failed to develop between the guard cells of the other stomata. Examination of leaves from group $\mathrm{c}$ plants revealed that many developing leaves also showed very restricted stomatal development.

Extended fogging of group $b$ plants reduced stomatal conductance $(g)$ and both assimilation rate $(A)$ and transpiration
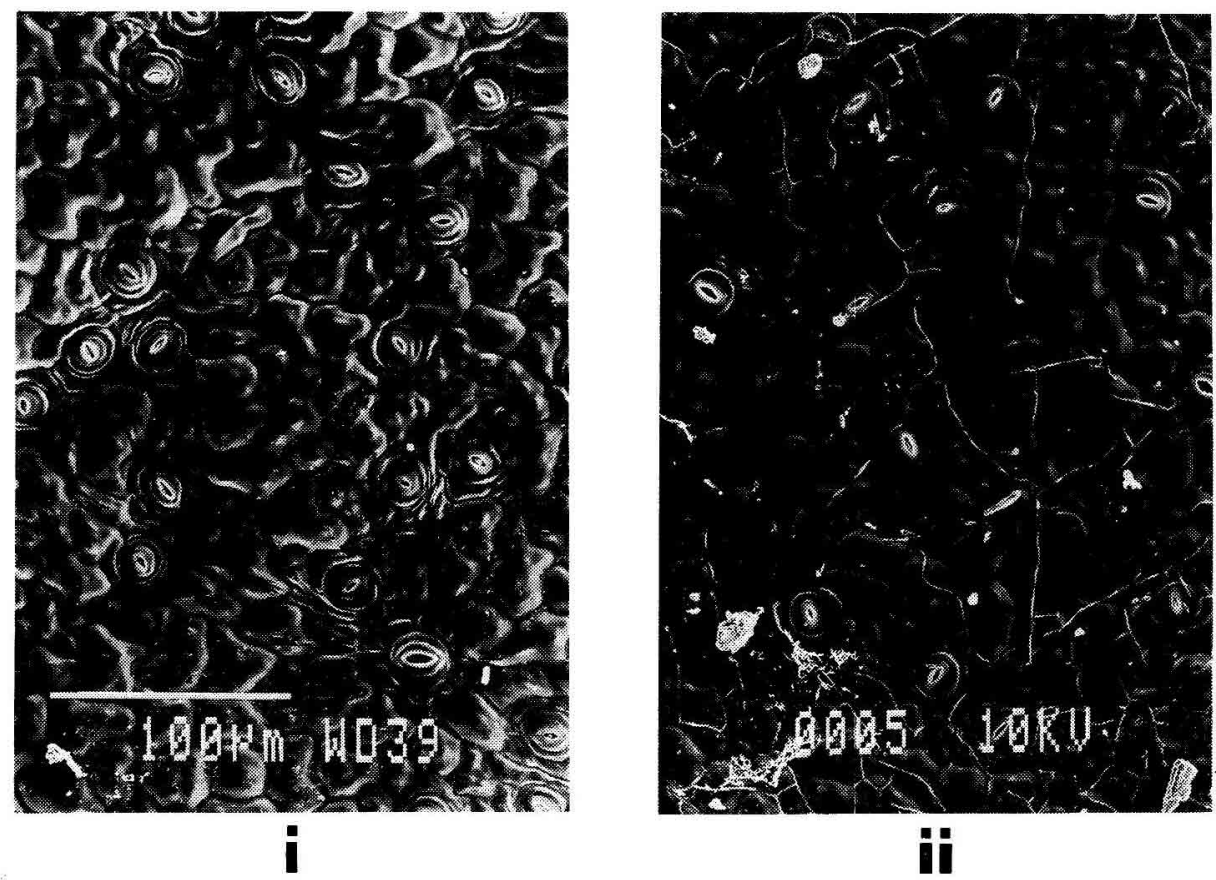

Fig. 1. Scanning electron micrograph of the abaxial surface of leaves of Photinia plants from group a that had either received $7 \mathrm{~d}$ fog (i) or $21 \mathrm{~d}$ fog (ii). 
Table I. Gas exchange data collected at $340 \mathrm{mmol} \mathrm{mol}^{-1} \mathrm{CO}_{2}$ (see text for explantation of symbols) $( \pm \mathrm{SD})$.

\begin{tabular}{|c|c|c|c|c|c|c|}
\hline Plants & $\begin{array}{l}\text { A }(\mu m o l \\
\left.m^{-2} s^{-1}\right)\end{array}$ & $\begin{array}{l}\mathrm{E}(\mathrm{mmol} \\
\left.m^{-2} s^{-1}\right)\end{array}$ & $\begin{array}{l}\mathrm{g}(\mathrm{mmol} \\
\left.m^{-2} s^{-1}\right)\end{array}$ & $\begin{array}{l}\mathrm{C}_{\mathrm{i}}(\mu \mathrm{mol} \\
\left.\mathrm{mol}^{-1}\right)\end{array}$ & $\mathrm{C}_{\mathrm{i}} / \mathrm{C}_{\mathrm{a}}$ & $\mathrm{A} / \mathrm{E}$ \\
\hline $\begin{array}{l}\text { Group b } \\
7 \mathrm{~d} \text { log }\end{array}$ & $-8.1 \pm 1.2$ & $-1.92 \pm 0.33$ & $179 \pm 40$ & $-211 \pm 25$ & $-0.66 \pm 0.05$ & $-0.004 \pm 0.002$ \\
\hline $\begin{array}{l}\text { Group b } \\
21 \mathrm{~d} \text { fog }\end{array}$ & $5.9 \pm 0.8$ & $1.35 \pm 0.10$ & $117 \pm 16$ & $225 \pm 45$ & $0.67 \pm 0.14$ & $0.004 \pm 0.001$ \\
\hline Group c & $4.7 \pm 1.57$ & $0.72 \pm 0.57$ & $47 \pm 25$ & $123 \pm 11$ & $0.38 \pm 0.04$ & $0.006 \pm 0.004$ \\
\hline
\end{tabular}

(E) (Table 1). $A / C_{i}$ analysis showed that extended fogging at high temperature increased the stomatal limitation of photosynthesis (results not shown). Group c plants showed very low stomatal conductances and rates of gas exchange (Table I). Intercellular $\mathrm{CO}_{2}$ concentration was very low and $C_{i} / C_{a}$ of these plants was approximately $60 \%$ of that found for most $\mathrm{C}_{3}$ plants (Wong et al., 1979).

\section{Discussion and Conclusion}

Extended fogging of Photinia plants at cool temperatures resulted in high mortality rates (group a). These plants showed only limited stomatal development (see Fig. 1) which might be expected to restrict gas exchange. Plants fogged for extended periods at higher temperatures (group b) showed restricted rates of photosynthesis due to enhanced stomatal limitations but this reduction was not substantial. Interestingly, plants in this group showed very low mortality rates even when fogged for $21 \mathrm{~d}$. We have not examined leaves of these plants under the SEM but it seems likely that they have developed relatively normally. Fogging at lower temperatures followed by cool and damp conditions in the greenhouse (group c) greatly restricted stomatal conductance and gas exchange and this was apparently due to restricted stomatal development. $C_{i}$ was close to the $\mathrm{CO}_{2}$ compensation point and this would be expected to enhance photorespiration rates with adverse effects on the capacity for carbon gain and successful growth and development.

It is suggested that a combination of low temperature and extended fogging allows only restricted stomatal development. This restricts $\mathrm{CO}_{2}$ uptake such that carbon gain eventually proves inadequate to sustain growth and development.

\section{References}

Atkinson C.J., Winner W.E. \& Mooney M.A. (1986) A field-portable exchange system for measuring carbon dioxide and water vapour exchange rates of leaves during fumigation with $\mathrm{SO}_{2}$. Plant Cell Environ. 9, 711-719

Farquhar G.D. \& Sharkey T.D. (1982) Stomatal conductance and photosynthesis. Annu. Rev. Plant Physiol. 33, 317.345

Wong S.C., Cowan I.R. \& Farquhar G.D. (1979) Stomatal conductance correlates with photosynthetic capacity. Nature 282, 424-426 